\title{
GiUlia MENSITIERI - «LE Plus BeAU MÉTIER DU MONDE». DANS LES COULISSES DE L'INDUSTRIE DE LA MODE [RECENSÃO]
}

\author{
José Mapril ${ }^{1}$ \\ CRIA-NOVA, Lisboa, Portugal
}

O recém-publicado livro de Giulia Mensitieri é uma análise teoricamente sofisticada e etnograficamente detalhada sobre determinados segmentos do mundo da moda em França. Recorrendo ao conceito de heterotopia (Foucault), a autora estabelece uma relação entre a dimensão imaterial, ideal e utópica do mundo da moda e as suas dimensões materiais e tangíveis. As heterotopias são aqui encaradas como lugares imaginários e mundos paralelos, mas também "espaços" e "experiências" que existem num lugar concreto. Nas palavras da autora:

En vérité, les hétérotopies ont une fonction sociale précise: en formant de 'contre-espaces', des lieux circonscrits de la 'deviation' et de l'altérité, elles définissent, par opposition, la norme. La mode en tant qu'hétérotopie joue aussi le rôle d'un leurre que, grâce a son apparence onirique, permet de normaliser des exceptions. La mode est à la fois un rêve, celui des défilés, des affiches et des vitrines, et une industrie mondiale engendrant des excès consuméristes, des profits exorbitants et des formes variées d'exploitation. (...) C'est cette double occupation d'un espace imaginaire et onirique et d'une réalité économique et professionnelle qui en fait 'un espace autre', une hétérotopie. (pp.15)

A indústria da moda, aquilo que a autora designa, em conjunto com outros autores, como o sistema-moda, revela-se aqui, por um lado, como um dos aspetos do capitalismo neoliberal, associado a imagens de prestígio, de beleza e de distinção (no sentido de Pierre Bourdieu) a diferentes escalas, e por outro, como um segmento do mercado de trabalho marcado pela precariedade e o outsourcing. O seu principal argumento é que a neoliberalização da moda criou condições especificas de trabalho, assentes na valorização da liberdade individual, da criatividade e da flexibilidade, e, simultaneamente, na precarização dos laços laborais e em formas de "remuneração" através de capitais simbólicos (prestígio e êxito) - o glamour labour.

Para revelar esta ambiguidade entre o glamour e a precariedade, o livro de Giulia está dividido em três partes: uma primeira, que explora a relação entre moda e capitalismo, numa espécie de economia política do sonho a uma escala global. Ao longo de três capítulos - "Fabriquer

$1 \quad$ Contato do autor: jmapril@fcsh.unl.pt. O livro foi publicado pela Editions La Découverte, Paris em Janeiro de 2018 (ISBN 9782707195401). 
le desir", "La Haute Culture" et "La circulation do Rêve" - vemos emergir uma indústria global e os regimes discursivos a ela associados.

$\mathrm{Na}$ segunda parte, a autora propõe uma escala intermédia, chamemos-lhe meso, onde se analisa os diferentes tipos de trabalho presentes na moda - vendedores, estilistas, manequins, agências, objectos, cidades, etc. - e a relação que mantêm com o sonho. Ao longo de quatro capítulos mergulhamos nas perspectivas de diferentes segmentos deste mercado de trabalho, desvelando-se como a precariedade é uma condição laboral recorrente, entre determinados segmentos.

Finalmente, na terceira parte, dá-se visibilidade às visões e às perspectivas dos trabalhadores da moda e procura-se pensar as suas subjetividades e a relação com a neoliberalização do sector. Um dos temas centrais é precisamente a forma como a precariedade é crescentemente interiorizada e incorporada, no sentido de habitus, e como os regimes laborais associados à moda privilegiam um tipo de trabalhador marcado pela flexibilidade, a criatividade e a incerteza.

Todos estes capítulos têm como base etnográfica a relação da autora com alguns interlocutores chave, interlocutores esses que, como sempre acontece nas nossas pesquisas, vão medear o acesso ao terreno. Como a própria autora reconhece e explicita, esta construção do "campo" permitiu aceder a determinadas perspectivas (dos trabalhadores criativos e flexíveis como fotógrafos, modelos, entre outros) e, simultaneamente, tornou outras visões menos evidentes (veja-se por exemplo, como a própria autora reconhece o limitado acesso direto ao mundo da alta costura). As condições de produção do conhecimento etnográfico implicam sempre escolhas e limites e, neste caso, a explicitação destes condicionalismos enriquece bastante a etnografia.

Através deste estudo de caso em torno da moda, o livro de Mensitieri possibilita uma aproximação etnográfica e histórica às reconfigurações neoliberais do trabalho no mundo contemporâneo, revelando como estas dinâmicas se manifestam noutros segmentos do mercado de trabalho, tais como empresas da economia social solidária, as universidades, a arte, entre muitos outros sectores criativos. A critica a Richard Florida e ao elogio que este faz à "classe criativa" assenta precisamente na forma como o "novo espírito do capitalismo", como the chamou Sennett (2007), produz uma sociedade de empresários, individualizada, e que abdica de quaisquer reivindicações laborais ou direitos sociais. $\mathrm{O}$ capitalismo, diz-nos Giulia, criou dispositivos de individuação que invisibilizam as desigualdades estruturais e modos de dominação através da criação de determinadas subjetividades. Em suma, o livro de Mensitieri é não apenas um excelente contributo para o conjunto específico de estudos sobre a moda, mas tem também um alcance mais vasto, possibilitando uma análise alargada sobre o neoliberalismo, a nova economia e o seu impacto na vida quotidiana de pessoas concretas.

\section{BIBLIOGRAFIA}

Sennet, Richard. 2007. A Cultura do Nova Capitalismo. Lisboa: Relógio D’Água. 